\title{
TOPONYMY AND CULTURAL VALUE OF VILLAGE NAMES IN BOJONG
}

\author{
Iis Rohmawati \\ Universitas Suryakancana \\ v.m.iisrohmawati158@gmail.com
}

\begin{abstract}
Abstrak
This article describes the aspects of toponymy and cultural values of village names in Bojong. The research method used descriptive, with observation, interview, and content analysis techniques. The research was carried out in Bojong, Karangtengah district, with the research objects of Ciburial, Ciroyom, and Kaum villages. The first result is, the three names of villages found in Bojong are categorized into three aspects of toponymy, namely the physical, social and cultural aspects. Secondly, there are cultural values in the stories of the three village names based on beliefs, social or individual interactions in groups and cultural values that relate to people's occupation from the past to the present. Therefore, the Village Head of Bojong can utilize local culture as a village asset.
\end{abstract}

Keywords: Toponymy aspects, cultural values.

\section{PENDAHULUAN}

Sastra lisan yang disebut literature transmitted orally atau unwritten literature lebih dikenal dengan istilah folklore. Sementara menurut Astika (2014:2), 'Tradisi lisan sinonim dari folklor lisan'. Hal itu karena sastra lisan merupakan bagian kebudayaan yang tersebar dan diwariskan turun-temurun baik yang disertai dengan gerak isyarat atau alat pembantu pengingat. Karena penyebarannya itu, terkadang sastra lisan tidak diketahui penemu atau penulisnya (tanpa nama).

Sama halnya dengan sastra lisan, nama Desa Bojong juga tidak diketahui penggagasnya. Kata "bojong" dapat memiliki arti dan cerita di balik penamaannya. Sebenarnya, nama tersebut berkaitan dengan bahasa dan budaya masyarakat saat itu karena tidak ada nama geografis yang tidak memiliki sejarah dan arti. Nama tersebut umumnya berkaitan dengan bahasa dan budaya sekaligus lingkungan tempat tinggal manusia.
Di Indonesia, tidak sedikit nama tempat berasosiasi dengan berbagai bentuk fenomena alam serta merupakan hasil dari kebudayaan. Misalnya, nama tempat yang berasosiasi dengan sungai, di Jawa Barat khususnya nama-nama terdapat di Desa Bojong biasanya diawali dengan " $c i$ " seperti Cisaat, Ciroyom, dan Ciburial. Semua itu adalah hasil dari kebudayaan, dan di dalamnya terdapat arti yang akan berkaitan dengan folklor (toponimi).

Jika toponimi dikaitkan dengan tujuan pembakuan nama rupa bumi cukup memprihatinkan apalagi bila dikaitkan dengan bahasa, sastra dan nilai budaya yang sudah mulai tergeser oleh kebudayaan asing. Dari hasil wawancara, mayoritas penduduk di Desa Bojong tidak tahu mengenai asal usul di balik penamaaan nama kampungnya masingmasing. Padahal folklor (toponimi) suatu daerah merupakan identitas yang membedakan dengan daerah lain. Nama-nama tersebut penting, karena bila toponimi hilang akan berimbas terhadap hilangnya 
kosakata bahasa Indonesia ataupun bahasa daerah.

Dalam toponimi, khususnya dalam penamaan kampung, terdapat nilai-nilai kehidupan. Nilai-nilai tersebut berkembang dan melekat serta menjadi contoh nyata dalam kehidupan, tetapi kurangnya informasi seperti buku-buku yang membahasa tentang cerita nama kampung mengakibatkan mayarakat kurang memahami hal tersebut. Oleh karena itu, pembiacaraan tentang aspek toponimi dan nilai budaya nama kampung menarik untuk didiskusikan. Misalnya, aspek toponimi apa saja yang terkandung dalam cerita namanama kampung dan bagaimana nilai budaya yang terkandung pada cerita namanama kampung di itu.

\section{METODE}

Metode yang digunakan yaitu deskriptif. Penelitian deskriptif (descriptive research) adalah suatu metode penelitian yang ditunjukkan untuk menggambarkan fenomena-fenomena yang ada, yang berlangsung pada saat ini atau saat yang lampau (Sukmadinata, 2015: 54).

Teknik yang digunakan adalah observasi, wawancara dan analisis isi. Penelitian dilaksanakan di Desa Bojong Kecamatan Karangtengah Kabupaten Cianjur. Subjek penelitian adalah namanama kampung yang ada di desa Bojong yaitu kampung Ciburial, Ciroyom dan Kaum, yang dideskripsikan berdasarkan aspek toponimi dan nilai budayanya. Ketiga kampung tersebut sebelumnya dipilih melalui sampel acak atau random dari 18 nama kampung di desa Bojong.

\section{HASIL DAN PEMBAHASAN}

Pada dasarnya, sastra lisan yang merupakan bagian dari folklor merupakan segala sesuatu yang tercakup dalam kehidupan kebudayaan rakyat seperti adatistiadat, kepercayaan, dongeng dan ungkapan (Rafiek, 2012: 54). Berdasarkan hal tersebut, sastra lisan dapat disebut folklor. Secara etimologis kata folklor berasal dari bahasa Inggris folklore, kata dasarnya folk artinya kolektif dan lore (Sobarna, 2004: 83). Foklor di Desa Bojong yang telah diteliti, berhubungan erat dengan toponimi atau penamaan tempat.

\section{Aspek Toponimi dan Nilai Budaya}

Toponimi merupakan pengetahuan yang mengkaji riwayat atau asal-usul nama tempat (Sudaryat, 2009:9). Sejarah toponimi sendiri dapat dilacak melalui penemuan peta-peta di masa silam di atas daun papyrus (di zaman peradaban Mesir Kuno) atau peta tablet tanah liat di lembah sungai Eufrat dan Tigris (Rais dkk, 2008: 55). Menurut Sudaryat (2009:12-18), penamaan tempat atau toponimi memiliki tiga aspek, yaitu: aspek perwujudan, aspek kemasyarakatan dan aspek kebudayaan.

Aspek wujudiah atau perwujudan (fisikal), berkaitan dengan kehidupan manusia yang cenderung menyatu dengan bumi sebagai tempat berpijak dan lingkungan alam sebagai tempat hidupnya. Sudaryat membagi lingkungan alam tersebut ke dalam tiga kelompok, yaitu latar perairan (fisikal), latar rupa bumi, dan latar lingkungan alam (biologis-ekologis). Aspek kemasyarakatan (sosial), berkaitan dengan interaksi sosial atau tempat berinteraksi sosial, termasuk kedudukan seseorang di dalam masyarakatnya, pekerjaan dan profesinya. Aspek kebudayaan seperti masalah mitologis, folklor, dan sistem kepercayaan (religi), pemberian nama tempat jenis ini sering pula dikaitkan dengan cerita rakyat yang disebut legenda, serta kepercayaan yang melekat dalm kehidupan masyarakat.

Dalam cerita rakyat ada berbagai nilai kehidupan yang dapat kita ambil sebagai pembelajaran, misalnya nilai 
kebudayaan. Menurut Budiati (2009: 14), kata budaya atau kebudayaan berasal dari kata bahasa sangsakerta budhayah yang merupakan bentuk jamak kata budhi yang berarti budi atau akal, sehingga kebudayaan secara sederhana diartikan sebagai hal-hal yang berkaitan dengan budi atau akal.

\section{Asal Usul Nama Kampung di Desa Bojong}

Berikut dipaparkan tiga nama kampung yang ditelaah yang meruakan nama-nama kamnpung yang terdapat di Desa Bojong

\section{Kampung Ciburial}

Dahulu kampung Ciburial, Ciroyom dan Kaum adalah hutan belantara yang begitu sunyi. Terdapat banyak sekali jenis hewan dan tumbuhan yang berukuran besar dan unik. Menurut cerita yang masih berkembang di masyarakat bahwa sebelum ketiga kampung ini ada, hutan tersebut begitu menyeramkan dan banyak mitos-mitos yang beredar di masyarakat. Terutama asal usul dari kampung Ciburial. Nama Ciburial diambil dari kata ci atau yang berarti cai dan dalam bahasa Indonesia berarti air, dan kata burial atau yang berarti menyembur/ mendidih/menggolak. Dikisahkan bahwa dahulu terdapat sumur tua di tengah empang. Awalnya lahan tersebut adalah kebun yang banyak sekali tumbuh pohon kirai. Setelah beberapa waktu sang pemilik empang ingin menggarap lahannya agar dapat ditanami padi. Akan tetapi, niatnya tidak dapat terpenuhi, karena muncul air yang besar dari sumur tersebut hingga proses menggarap pun terhenti. Lalu si pemilik lahan menutup lubang sumur tersebut dengan sindang atau mangkok. Sindang tersebut bukanlah sindang biasa. Setelah itu, air pun tidak keluar lagi dari sumur tersebut. Akan tetapi, ada hal yang aneh setelah air di sumur tersebut tidak keluar, sekarang malah keluar di kampung Babakan secara tiba-tiba. Setelah kejadian tersebut banyak mitos yang beredar bahwa sumur tersebut angker. Dikatakan bahwa bila ada orang yang berniat buruk mendekati sumur tersebut akan sakit. Serta banyak yang percaya bahwa terdapat makhluk gaib yang menjaga sumur tersebut seperti ular raksasa, harimau dan lain-lain. Nama Ciburial pun sudah ada sejak dulu. Tentang siapa dan kapan yang mengesyahkan nama tersebut tidak ada yang tahu. Kemungkinan si pemilik lahan tersebut atau orang lain. Kini, nama kampung Ciburial selalu dikaitkan dengan kampung Cisaat yang bersebrangan hanya terpisahkan oleh jalan raya saja.

Kampung ini memiliki tanah yang subur, sehingga banyak warga yang berkebun seperti menanam padi dan sayuran yang merupakan pekerjaan sehari-hari mereka. Panen padi pun dilakukan sekitar 3 kali dalam setahun. Selain itu, terdapat Pondok Pesantren di kampung Ciburial dan Kaum. Lalu, ada seorang haji yang bernama bapak H. Bakri yang sangat terkenal di kampung Ciburial. Beliau pernah membuatkan saluran air agar air tersebut dapat mengalir ke mesjid. Mesjid tersebut adalah satu-satunya tempat ibadah yang digunakan warga kala itu. Masyarakat kampung Ciburial begitu ramah dengan perilaku dan tutur katanya yang sopan. Dalam kesehariannya, masyarakat dari kampung Ciburial sering menggunakan bahasa Sunda.

\section{Kampung Kaum}

Kampung Kaum yang terletak tidak jauh dari kampung Ciburial. Kata Kaum yang berarti kantor dan zaman dulu terdapat kantor KUA di sana sehingga masyarakat menyebutnya Kaum. Kenapa demikian? Karena orang dulu menyebut kantor KUA dengan sebutan Kaum. Sebenarnya Kaum dan Ciburial adalah satu kampung. Namun, semakin pesatnya pertumbuhan penduduk dibagilah menjadi dua kampung oleh kepala desa kala itu. Salah satunya disebut kampung Kaum karena di sana terdapat kantor KUA. Keadaan kantor KUA saat itu sulit untuk disebutkan karena kantornya bersatu dengan bangunan masjid. Bahkan bisa dibilang kantor KUA adalah mesjid setempat kala itu. Namun, sejak dulu penduduk kampung kaum 
memiliki solidaritas yang tinggi dalam bersosialisasi. Kampung ini memiliki tanah yang subur, sehingga banyak warga yang berkebun seperti menanam padi dan sayuran yang merupakan pekerjaan sehari-hari mereka. Panen padi pun dilakukan sekitar 3 kali dalam setahun. Masyarakat kampung Kaum begitu ramah dengan perilaku dan tutur katanya yang sopan. Dalam kesehariannya, masyarakat dari kampung Kaum tersebut sering menggunakan bahasa Sunda.

\section{Kampung Ciroyom}

Kampung Ciroyom yang sekarang terkenal. Kata Ciroyom berasal dari kata ci atau yang berarti cai dan dalam bahasa Indonesia berarti air, dan kata royom yang berarti merunduk dan rimbun. Zaman dulu masih banyak orang yang percaya akan halhal gaib. Dikisahkan ada seorang ulama yang begitu taat ibadah dan sering melakukan medi ka gusti Allah atau tapa. Ulama tersebut berpuasa selam 40 hari 40 malam. Beliau bertapa di bawah pohon kelapa yang merunduk dan rimbun. Dengan penuh perjuangan ulama tersebut menahan lapar, haus dan godaan yang terdapat di tempat tersebut. Walaupun dengan perjuangan yang sulit dan panjang, akhirnya ulama tersebut berhasil. Setelah puasanya selesai Ia pun membatalkan puasanya dengan meminum air yang menetes jatuh dari daun kelapa tersebut. Masyarakat percaya bahwa ulama tersebut bukan orang sembarangan. Maka saat ulama tersebut berkata "Ieu kampung namina ciroyom tong dirobih, kumargi kin bakal kasohor". Hingga kini kampung tersebut terkenal dengan sebutan kampung Ciroyom. Tidak ada yang ingin mengganti nama tersebut karena takut dengan akibat yang akan menimpa mereka nantinya. Kampung ini memiliki tanah yang subur, sehingga banyak warga yang berkebun seperti menanam padi dan sayuran yang merupakan pekerjaan sehari-hari mereka. Panen padi pun dilakukan sekitar 3 kali dalam setahun. Masyarakat kampung Ciroyom begitu ramah dengan perilaku dan tutur katanya yang sopan. Dalam kesehariannya, masyarakat dari kampung Ciroyom tersebut sering menggunakan bahasa sunda.

Setelah dikaji, dapat dikemukanan pertama, ketiga nama kampung yang terdapat di Desa Bojong dikategorikan ke dalam tiga aspek toponimi yaitu aspek fisikal, kemasyarakatan dan kebudayaan. Kedua, terdapat nilai budaya dalam cerita ketiga nama kampung tersebut yaitu nilai budaya berdasarkan kepercayaan, sosial atau interaksi individu dalam kelompok dan nilai budaya yang berhubungan dengan mata pencaharian masyarakat sejak dulu hingga sekarang.

Dari penelitian diperoleh informasi awal mengenai desa Bojong. Desa Bojong berlokasi di Jl. Raya Bandung No.17, Kecamatan Karangtengah. Kecamatan Karangtengah memiliki luas wilayah: 300.030 hektar dengan batas-batas sebagai berikut : 1) Sebelah Utara berbatasan dengan Desa Sindanglaka/Desa Sukataris, 2) Sebelah Selatan berbatasan dengan Desa Sabandar/ Desa Hegarmanah, 3) Sebelah Barat berbatasan dengan Kelurahan Muka/Desa Sabandar dan 4) Sebelah Timur berbatasan dengan Desa Sukamulya/Desa Hegarmanah.

Desa Bojong resmi berdiri pada tahun 1924. Desa Bojong kini memiliki jumlah penduduk 18.025 jiwa dan 4.838 kepala keluarga, dengan mayoritas penduduknya beragama islam. Terdapat $18 \mathrm{RW}$ dan $70 \mathrm{RT}$ di Desa Bojong.

Setelah mencari tahu dengan bertanya ke desa mengenai siapa sajakah tokoh yang mengetahui cerita asal usul nama-nama kampung di Desa Bojong, dan hasilnya sangat memprihatinkan bahwa hanya ada satu orang saja yang mengetahui semua itu yakni Bapak Kepala Desa dan sekaligus pupuhu kampung Ciburial. Menurut beberapa orang yang ditemui di kantor desa, faktor utama tidak ada yang mengetahui cerita tersebut karena penyebarannya yang dilakukan secara lisan serta belum pernah ada yang meneliti atau dalam bentuk dokumentasi. Para ририhи 
kampung yang dulu pun sudah tidak ada dan yang tersisa sudah "pikun".

Kegiatan penelaahan dilanjutkan dengan wawancara yang berlangsung di rumah Bapak Djarnudji, Desa Bojong Kecamatan Karangtengah Kabupaten Cianjur. Waktu wawancara terjadi pada hari kamis 28 Juni 2018, pukul 19.30 WIB. Bapak Djarnudji merupakah tokoh/sesepuh di kampung Ciburial dan Kepala Desa Bojong yang masih mengetahui cerita asal usul nama-nama kampung di desa Bojong. Bentuk bahasa yang terjadi adalah bahasa lisan dengan menggunakan bahasa Sunda.

$\begin{array}{ll}\text { Aspek Perwujudan (Latar } & \text { Kspek Toponimi } \\ \text { perarian atau hidrologis) } & \text { Kerarti cai dan dalam bahasa Indonesia berarti air, dan } \\ & \text { kata burial atau yang berartim menyembur/menggolak/ } \\ \text { mendidih. Dikisahkan bahwa dahulu terdapat sumur tua } & \text { di tengah empang. Awalnya lahan tersebut adalah } \\ & \text { kebun yang banyak sekali tumbuh pohon kirai. } \\ & \text { Setelah beberapa waktu sang pemilik empang ingin } \\ & \text { menggarap lahannya agar dapat ditanami padi. Namun, } \\ & \text { niatnya tidak dapat terpenuhi, karena muncul air yang } \\ & \text { besar dari sumur tersebut hingga proses menggarap pun } \\ \text { terhenti". }\end{array}$

Dari hasil wawancara diketahui bahwa kampung Ciburial, Ciroyom dan Kaum memiliki cerita yang mengandung aspek toponimi dan nilai budaya yang mempengaruhi penamaannya. Berdasarkan cerita Ciburial berawal dari sumur yang mengeluarkan air, Ciroyom berawal dari ulama yang bertapa di bawah pohon, dan Kaum berasal dari kantor yang dulunya disebut kantor KUA.

Kampung Ciburial sendiri memiliki beberapa mitos yang beredar seperti penghuni sumur dan kekuatan gaib dari sumur tersebut. Ketiga kampung itu memiliki masyarakat yang ramah dan santun, serta pekerjaan sehari-hari mereka adalah bertani dan berkebun. Informasi tentang asal usul nama kampung di Desa Bojong ini, selanjutnya dianalisis berdasarkan aspek toponimi dan nilai budayanya.

\section{Aspek Toponimi dan Nilai Budaya}

Dari hasil wawancara yang dilakukan petutur dan mitra tutur tersebut diolah dan dibuat transkip data berupa teks cerita. Pada bagian ini, akan diuraikan hasil analisis mengenai aspek toponimi dan nilai yang ada dalam cerita asal usul nama kampung di Desa Bojong.

\section{Kampung Ciburial}

Tabel 1: Aspek Toponimi dalam Cerita Kampung Ciburial 
Tabel 2: Nilai Budaya dalam Cerita Kampung Ciburial memenuhinya seseorang harus bekerja. Berdasarkan hal tersebut mata pencaharian

$\begin{array}{ll}\text { No } & \begin{array}{l}\text { Nilai budaya yang } \\ \text { berkaitan dengan } \\ \text { kepercayaan masyarakat } \\ \text { (hal-hal gaib). }\end{array} \\ 2 & \begin{array}{l}\text { Nilai budaya berdasarkan } \\ \text { sosialisasi antar individu } \\ \text { yang masih terjalin baik } \\ \text { (tindakan, bahasa, dan } \\ \text { sikap } \\ \text { Nilai budaya berdasakan } \\ \text { unsur mata pencaharian }\end{array}\end{array}$

Dilihat dari tabel di atas diketahui terdapat nilai budaya yang berkaitan dengan kepercayaan masyarakat terhadap hal-hal gaib, berdasarkan interaksi dan mata pencaharian. Nilai budaya berdasarkan kepercayaaan suatu masyarakat yang sering terjadi di dalam kelompok masyarakat yaitu tentang kepercayaan mereka terhadap hal-hal gaib dan itu sudah
Kutipan Teks

"Dikatakan bahwa bila ada orang yang berniat buruk mendekati sumur tersebut akan sakit. Serta banyak yang percaya bahwa terdapat makhluk gaib yang menjaga sumur tersebut seperti ular raksasa, harimau dan lain-lain".

"Masyarakat kampung Ciburial begitu ramah dengan perilaku dan tutur katanya yang sopan. Dalam kesehariannya, masyarakat dari kampung Ciburial sering menggunakan bahasa Sunda"

"Kampung Ciburial memiliki tanah yang subur, sehingga banyak warga yang berkebun seperti menanam padi dan sayuran yang merupakan pekerjaan sehari-hari mereka"

setiap orang pun akan beragam pula dan itu sudah terjadi sejak dulu setelah manusia bermukim dan mengenal kebudayaan. Mata pencaharian dalam cerita kampung Ciburial lebih ke bertani dan berkebun.

\section{Kampung Kaum}

Tabel 3: Aspek Toponimi dalam Cerita Kampung Kaum

$\begin{array}{ll}\text { Aspek Kemasyarakatan } & \text { Aspek Toponimi } \\ \text { (Nama tempat) } & \begin{array}{l}\text { "Kata Kaum yang berarti kantor dan } \\ \text { zaman dulu terdapat kantor KUA di sana, } \\ \text { sehingga masyarakat menyebutnya } \\ \text { Kaum" }\end{array}\end{array}$

menjadi budaya sejak dulu. Mitos dan tahayul sering menjadi topik paling menarik dalam suatu kelompok masyarakat. Contohnya mitos pada sumur di kampung Ciburial.

Nilai budaya berdasarkan interaksi yang terjalin sejak dulu antar kelompok masyarakat. Walaupun ada perubahan, akan tetapi dulu interaksi yang terjalin antarmasyarakat masih begitu harmonis dengan menganggap satu sama lain adalah keluarga. Terakhir, kebutuhan hidup seseorang beragam dan untuk
Berdasarkan hasil analisis dapat dideskripsikan bahwa dalam cerita kampung Kaum memiliki aspek toponimi yaitu aspek kemasyarakatan. Aspek kemasyarakatan yang dimaksud yaitu berkaitan dengan nama tempat yang di dalamnya terdapat interaksi sosial. Terlihat jelas bahwa penamaan tempat yang diambil dari nama bangunan saat itu. Kaum yang dulunya bermula dari sebuah kantor KUA. KUA dulu disebut kaum oleh masyarakat sehingga kata "kaum" berasal dari sebuah 
bangunan atau nama tempat berinteraksi sosial.

Tabel 4: Nilai Budaya dalam Cerita Kampung Kaum bermukim dan mengenal kebudayaan. Mata pencaharian dalam cerita kampung Kaum pun lebih ke bertani dan berkebun.

\section{Kampung Ciroyom}

\begin{tabular}{|c|c|c|}
\hline No & Nilai Budaya & Kutipan Teks \\
\hline 1 & $\begin{array}{l}\text { Nilai budaya berdasarkan } \\
\text { sosialisasi antarindividu } \\
\text { yang masih terjalin baik } \\
\text { (tindakan, bahasa dan } \\
\text { sikap) }\end{array}$ & $\begin{array}{l}\text { "Penduduk kampung kaum memiliki } \\
\text { solidaritas yang tinggi dalam bersosialisasi". } \\
\text { "Masyarakat kampung Kaum begitu ramah dengan } \\
\text { perilaku dan tutur katanya yang sopan" }\end{array}$ \\
\hline 2 & $\begin{array}{l}\text { Nilai budaya berdasakan } \\
\text { unsur mata pencaharian }\end{array}$ & $\begin{array}{l}\text { "Kampung Kaum ini memiliki tanah yang subur, } \\
\text { sehingga banyak warga yang } \\
\text { berkebun seperti menanam padi dan } \\
\text { sayuran yang merupakan pekerjaan sehari-hari } \\
\text { mereka" }\end{array}$ \\
\hline
\end{tabular}

Dilihat dari tabel tampak bahwa terdapat nilai budaya yang berkaitan dengan interaksi sosial dan mata pencaharian. Sama
Tabel 5: Aspek Toponimi dalam Cerita Kampung Ciroyom

\begin{tabular}{|c|c|c|}
\hline No & Aspek Toponimi & Kutipan Teks \\
\hline 1 & $\begin{array}{l}\text { Aspek perwujudan (latar } \\
\text { perairan atau hidrologis) }\end{array}$ & $\begin{array}{l}\text { "Kata Ciroyom berasal dari kata ci atau } \\
\text { yang berarti cai dan dalam bahasa } \\
\text { Indonesia berarti air, dan kata royom yang } \\
\text { berarti merunduk dan rimbun". }\end{array}$ \\
\hline 2 & Aspek kebudayaan & $\begin{array}{l}\text { "Dikisahkan ada seorang ulama yang } \\
\text { bgitu taat ibadah dan sering melakukan } \\
\text { semedi ka gusti Allah atau tapa. Ulama } \\
\text { tersebut berpuasa selam } 40 \text { hari } 40 \text { malam } \\
\text { saat tapanya. Beliau bertapa di bawah } \\
\text { pohon kelapa yang merunduk dan } \\
\text { rimbun. Setelah puasanya selesai Ia pun } \\
\text { membatalkan puasanya dengan meminum } \\
\text { air yang menetes jatuh dari daun kelapa } \\
\text { tersebut". }\end{array}$ \\
\hline
\end{tabular}

halnya dengan kampung Ciburial, kampung Kaum mengandung unsur nilai budaya berdasarkan Interaksi sosial yang begitu harmonis sejak dulu. Akan tetapi, seiring waktu selalu ada perubahan. Terakhir, sama dengan masyarakat kampung Ciburial masyarakat kampung Kaum memiliki keberagaman dalam kebutuhan hidup dan untuk memenuhinya seseorang harus bekerja. Berdasarkan hal tersebut mata pencaharian setiap orang pun akan beragam pula dan itu sudah terjadi sejak dulu setelah manusia

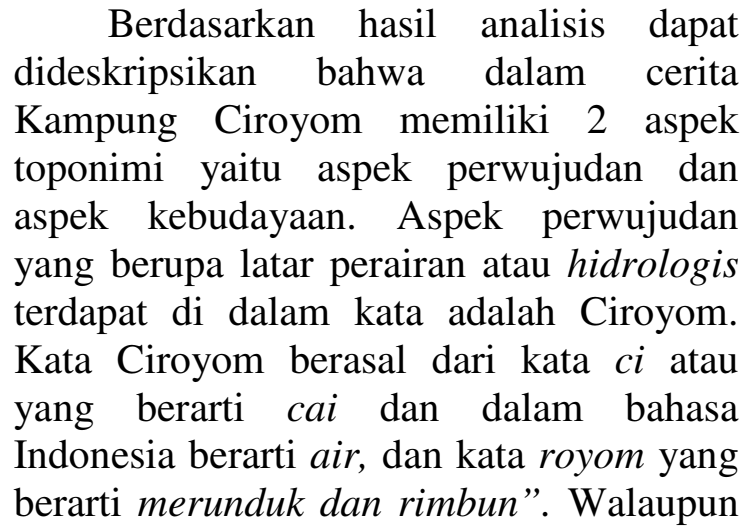


kata royom mengarah ke pohon, tetapi awal kata $c i$ yang berarti air mengarah ke sebuah air dan latar hidrologis kampung Ciroyom, yang sekaligus mempengaruhi penamaannya. mustahil. Bahkan masyarakat di kampung Ciroyom percaya bahwa bila mengganti nama kampung mereka akan ditimpa sial.

Tabel 6: Nilai Budaya dalam Cerita Kampung Ciroyom

1 Nilai budaya berdasarkan keperca-

2 Nilai budaya berdasarkan sosialisasi antarindividu yang masih terjalin baik (tindakan, bahasa dan sikap)

3. Nilai budaya berdasakan unsur mata pencaharian
Kutipan Teks

Zaman dulu masih banyak orang yang percaya akan hal-hal gaib. Dikisahkan ada seorang ulama yang begitu taat ibadah dan sering melakukan medi ka gusti Allah atau tersebut berpuasa selam 40 hari 40 malam. Beliau bertapa di bawah pohon kelapa yang merunduk dan rimbun.

Dengan penuh perjuangan ulama tersebut menahan lapar, haus dan godaan yang terdapat di tempat tersebut. Walaupun dengan perjuangan yang sulit dan panjang, akhirnya ulama tersebut berhasil. Setelah puasanya selesai Ia pun membatalkan puasanya dengan meminum air yang menetes jatuh dari daun kelapa tersebut. Masyarakat percaya bahwa ulama tersebut bukan orang sembarangan. Maka saat ulama tersebut berkata "Ieu kampung namina Ciroyom tong dirobih, kumargi kin bakal kasohor". Hingga kini kampung tersebut terkenal dengan sebutan kampung Ciroyom. Tidak ada yang ingin mengganti nama tersebut karena takut dengan akibat yang akan menimpa mereka nantinya.

"Masyarakat kampung Ciroyom begitu ramah dengan perilaku dan tutur katanya yang sopan"

"Kampung Ciroyom memiliki tanah yang subur, sehingga banyak warga yang berkebun seperti menanam padi dan sayuran yang merupakan pekerjaan seharihari mereka"

Aspek kebudayaan yang dikaitkan dengan unsur kebudayaan seperti masalah mitologis, folklor, dan sistem kepercayaan. Aspek ini berkaitan erat dengan ceritacerita legenda atau suatu kepercayaan yang ada dalam sekelompok masyarakat. Pada cerita kampung Ciroyom terlihat jelas bahwa dahulu ada orang yang masih suka bertapa dan percaya akan sesuatu yang
Dilihat dari tabel tampak terdapat nilai budaya yang berkaitan dengan kepercayaan masyarakat terhadap hal-hal gaib, berdasarkan interaksi dan mata pencaharian. Sebenarnya, tidak jauh berbeda dengan kampung Ciburial dan Kaum. Kampung Ciroyom pun mengandung nilai budaya yang berkaitan erat dengan 
kepercayaan mengenai sesuatu atau hal gaib. Akan tetapi, tidak hanya itu terdapat pula nilai budaya yang berhubungan dengan intraksi sosial dan mata pencaharian masyarakat yang memang sejak dulu. Masyarakat kampung Ciroyom terkenal akan keramahannya dan pekerja keras.

\section{SIMPULAN}

Berdasarkan hasil penelitian yang telah dilakukan, diperoleh simpulan sebagai berikut: Aspek toponimi yang terdapat dalam cerita asal usul nama kampung di Desa Bojong terdiri atas aspek fisikal, kemasyarakatan dan kebudayaan. Berdasarkan aspek toponimi ada juga nama kampung yang memiliki aspek penamaan lebih dari satu aspek. Konsep keberadaan aspek toponimi ini masih dapat dijangkau oleh pemahaman manusia pada umumnya. Karena latar belakang penamaan berhubungan dengan tempat tinggal mereka ataupun ciri khas yang ada di tempat tersebut; dan nilai budaya yang terdapat dalam cerita asal usul nama kampung di Desa Bojong meliputi nilai budaya berdasarkan kepercayaan, sosial atau interaksi individu dalam kelompok dan nilai budaya yang berhubungan dengan mata pencaharian masyarakat sejak dulu hingga sekarang.

Saran untuk Kepala Desa Bojong agar memanfaatkan bentuk kebudayaan lokal sebagai aset desa, serta untuk menjaga dan melestarikan kebudayaan lokal yang terdapat di lingkungan sendiri.

\section{DAFTAR PUSTAKA}

Astika, I Made dan I Nyoman Yasa. 2014. Sastra Lisan (Teori dan Penerapannya). Yogyakarta: Graha Ilmu.

Budiati, Atik Catur. 2009. Sosiologi Kontekstual. Jakarta: CV Mediatama.

Rafiek, M. 2012. Teori Sastra: Kajian Teori dan Praktik. Bandung: PT Refika Aditama.

Rais, Jacub dkk. 2008. Toponimi: Sejarah Budaya yang Panjang dari Pemukiman Manusia dan Tertib Administrasi. Jakarta: Pradnya Paramita.

Sobarna, Cece, T. Wartini dan T. Ampera. 2004. Bahasa dan Sastra Daerah di Kabupaten Tanggerang Pengkajian Budaya dan Nilai-Nilai Tradisional. Bandung: Pemerintah Kabupaten Tangerang.

Sudaryat, Yayat dkk. 2009. Toponimi Jawa Barat (Berdasarkan Cerita Rakyat). Bandung: Dinas Pariwisata dan Kebudayaan Propinsi Jawa Barat.

Sukmadinata, Nana Syaodih. 2015. Metode Penelitian Pendidikan. Bandung: PT. Remaja Rosdakarya. 